\title{
Micromechanical Behavior Related to the Nanostructure of Biodegradable Polyesters
}

\author{
M. E. Cagiao, ${ }^{1}$ P. Buzin, ${ }^{2 *}$ H. R. Kricheldorf, ${ }^{2}$ S. S. Funari, ${ }^{3}$ F. J. Baltá Calleja ${ }^{1}$ \\ ${ }^{1}$ Instituto de Estructura de la Materia, Consejo Superior de Investigaciones Científicas, Serrano 119, \\ 28006 Madrid, Spain \\ ${ }^{2}$ Institut für Technische und Makromolekulare Chemie der Universität, Bundestrasse 45, D-20146 Hamburg, Germany \\ ${ }^{3}$ Beamline A2, Deutsches Elektronen Synchrotron, Noktestrasse 85, D-22607 Hamburg, Germany
}

Received 28 October 2008; accepted 19 March 2009

DOI 10.1002/app.31432

Published online 27 April 2010 in Wiley InterScience (www.interscience.wiley.com).

\begin{abstract}
The microhardness of a series of biodegradable polyesters was determined. The nanostructural features of these materials were studied by wide-angle X-ray scattering (WAXS), small-angle X-ray scattering (SAXS), and differential scanning calorimetry. Analysis of the SAXS and WAXS patterns allowed direct derivation of the degree of crystallinity and crystal thickness values, and correlations of the micromechanical properties are presented. The differen-
\end{abstract}

ces in the thermal and mechanical properties exhibited by the studied systems and the ones found in other aromatic polyesters are explained as due to the different chemical natures of the monomeric units. (c) 2010 Wiley Periodicals, Inc. J Appl Polym Sci 117: 2591-2596, 2010

Key words: calorimetry; hardness; microstructure; polyesters; SAXS

\section{INTRODUCTION}

Aliphatic polyesters have received much attention in the past 2 decades because these materials are, in many cases, biodegradable by hydrolytic degradation. The reason for this behavior is the electrophilic character shown by the aliphatic ester group. Thus, some aliphatic polyesters, such as poly( $\varepsilon$-caprolactone), poly(ethylene adipate), and poly(butylene succinate), have been commercialized as biodegradable materials. The number of pharmaceutical and biomedical applications for these polymers is continuously increasing. ${ }^{1-3}$ One of the ways to obtain polyesters with a wide range of applications is through the modification of the chemical structure of the

*Present address: Institute of Problems of Chemical Physics, Akademik Semenov Avenue 1, Chernogolovka, Moscow Region, 142432, Russian Federation.

Correspondence to: F. J. Baltá Calleja (embalta@iem.cfmac. csic.es.).

Contract grant sponsor: Spanish Ministry of Science and Innovation; contract grant number: FIS2004-01331.

Contract grant sponsor: Alexander von Humboldt Foundation (to F.J.B.C. for work performed at the Institute for Technical and Macromolecular Chemistry of the University of Hamburg).

Contract grant sponsor: European Community Research Infrastructure Action [through the FP6 program Structuring the European Research Area (project II-07-031 EC) for the experimental work carried out at Hamburger Synchrotronstrahlungslabor, Deutsches Elektronen Synchrotron, Hamburg, Germany].

Journal of Applied Polymer Science, Vol. 117, 2591-2596 (2010) (C) 2010 Wiley Periodicals, Inc. polymers, for instance, by the introduction of new functional groups in the monomer. The presence of a double or a triple bond in the glycol or dialcohol of the monomeric unit allows further modification of the polyester by means of chemical reactions, such as the addition of bromine, epoxidation, or crosslinking.

A series of aliphatic polyesters (samples 1-6) were synthesized in recent years by Kricheldorf and coworkers. ${ }^{4-6}$ The chemical formulas are given in Figure 1. As shown, samples 1 and 2 are saturated polyesters based on 1,4-butane diol. Samples 3 and 4 are unsaturated polyesters based on cis-1,4-butene diol (cBeD), a glycol unit with a cis double bond. Finally, samples 5 and 6 are also unsaturated polyesters that contain a triple bond in the glycol unit, 1,4-butyne diol (ByD). As shown in Figure 1, the two polyesters of each pair differ only in the number of methylene groups of the diacid unit, which is 4 or 8 , respectively. Samples 1 and 2 are the better known polyesters and have been investigated for a long time. ${ }^{4,7-17}$ There have also been some studies performed on samples $3^{18,19}$ and $4 .^{18,20}$ In addition, Kricheldorf et al. ${ }^{5}$ recently published an article devoted to samples 3 and 4 . However, to our knowledge, there have only been a few studies dealing with samples $5^{19}$ and $6^{21}$ before the study just reported by Kricheldorf et al. ${ }^{6}$ In this publication, ${ }^{6}$ three methods developed for the synthesis of samples 5 and 6 with high molecular weights were presented and discussed. Method A consisted of the thermal transesterification of ByD with the dimethyl ester of a sebacic acid in bulk catalyzed by $\mathrm{Ti}(\mathrm{OBu})_{4}$. 


\section{-[O- $\mathrm{CH}_{2} \mathrm{CH}_{2} \mathrm{CH}_{2} \mathrm{CH}_{2}$-O-CO- $\left.\left(\mathrm{CH}_{2}\right)_{\mathrm{n}}-\mathrm{CO}\right]-$}

\author{
Sample 1: $n=4$. Sample 2: $n=8$ \\ -[O- $\left.\mathrm{CH}_{2}-\mathrm{HC}=\mathrm{CH}-\mathrm{CH}_{2}-\mathrm{O}-\mathrm{CO}-\left(\mathrm{CH}_{2}\right) \mathrm{n}-\mathrm{CO}-\right]$
}

(Cis-form)

\author{
Sample 3: $n=4$. Sample 4: $n=8$ \\ -[O- $\mathrm{CH}_{2}-\mathrm{C} \equiv \mathrm{C}-\mathrm{CH}_{2}-\mathrm{O}-\mathrm{CO}-\left(\mathrm{CH}_{2}\right)$ n- $\left.\mathrm{CO}-\right]$
}

\author{
Sample 5: $n=4$. Sample 6: $n=8$ \\ Sample 1: Poly(butanediol adipate) \\ Sample 2: Poly(butanediol sebacate) \\ Sample 3: Poly(butenediol adipate) \\ Sample 4: Poly(butenediol sebacate) \\ Sample 5: Poly(butynediol adipate) \\ Sample 6: Poly(butynediol sebacate)
}

Figure 1 Chemical formulas of the studied aliphatic polyesters.

In method $\mathrm{B}$, the direct polycondensation of $\mathrm{ByD}$ with sebacic acid was essayed with $p$-toluene sulfonic acid as a catalyst. Finally, method $C$ dealt with the polycondensation of $\mathrm{ByD}$ with diacid dichlorides (adipoyl and sebacoyl dichlorides, in our case) in the presence of pyridine as a catalyst. The last method, method $\mathrm{C}$, was the preferred one for obtaining polyesters with satisfactory molecular weights and a smaller fraction of secondary reaction products.

In the preceding studies, the correlation between the nanostructure and the micromechanical properties of the polymers was well characterized. ${ }^{22-26}$

The aim of this study was to investigate the nanostructure and micromechanical properties of these three different types of polyesters, that is, saturated, unsaturated with a cis double bond, and unsaturated with a triple bond in the monomeric unit.

\section{EXPERIMENTAL}

\section{Materials}

Samples 1 and 2 were synthesized according to a method previously developed in our laboratory. ${ }^{4}$ In this method, we essentially used the cyclic initiator 2,2-dibutyl-2-stanna-1,3-dioxepane (DSDOP) to react with a dicarboxylic acid dichloride, thus obtaining the corresponding polyester based on 1,4-butane diol. After repeated washing and purification, the final products were dried in vacuo at $40^{\circ} \mathrm{C}$.

Samples 3 and 4 were prepared by the polycondensation of cis-1,4-butenediol with dicarboxylic acid dichlorides in the presence of pyridine as a catalyst. ${ }^{5}$
After precipitation and filtration, the polyesters were dried in vacuo at $20^{\circ} \mathrm{C}$.

Samples 5 and 6 were obtained by the polycondensation of butyne-1,4-diol (ByD) with dicarboxylic acid dichlorides with pyridine as a catalyst. ${ }^{6}$ After precipitation and filtration, the final products were dried in vacuo at $20^{\circ} \mathrm{C}$ overnight.

The samples were compression-molded in a press at $22 \pm 1^{\circ} \mathrm{C}$ before their characterization by different methods.

\section{Techniques}

The samples were characterized by wide-angle $X$-ray scattering (WAXS) and small-angle X-ray scattering (SAXS), differential scanning calorimetry (DSC), and microhardness $(H)$ measurements.

For the WAXS study, a Seifert diffractometer (reflection mode) was used. The working conditions were as follows: voltage $=40 \mathrm{kV}$, intensity $=$ $35 \mathrm{~mA}$, angular range $=5-35^{\circ}(2 \theta)$, scan rate $=0.05$, and slits $=0.3$ and 0.1 .

SAXS patterns were obtained with a synchrotron radiation source at the $\mathrm{A} 2$ beamline in Hamburger Synchrotronstrahlungslabor, Deutsches Elektronen Synchrotron, Hamburg. Scattering patterns were recorded with a one-dimensional detector. A wavelength $(\lambda)$ of $0.15 \mathrm{~nm}$ was used. The sample-to-detector distance was $200 \mathrm{~cm}$. The data were corrected for the detector response and beam intensity. Application of Bragg's law to the scattering maxima was used to calculate the long period $(L)$.

DSC measurements were performed in a PerkinElmer DSC-7 (Shelton, CT) differential scanning calorimeter in an inert $\mathrm{N}_{2}$ atmosphere. The temperature range covered was $30-130^{\circ} \mathrm{C}$. The heating rate was $10^{\circ} \mathrm{C} / \mathrm{min}$. Typical sample weights were about $5 \mathrm{mg}$. Table I summarizes the melting temperature $\left(T_{m}\right)$ and the melting enthalpy $\left(\Delta H_{m}\right)$ values of the samples.

Microhardness $H$ was measured at room temperature with a Leitz tester (Wetzlar, Germany) equipped with a Vickers diamond pyramid. $H$ values were derived from the optical measurement of the residual impression left behind upon load release, according to $H=1.854 P / d^{2}$, where $d$ is the length of the indentation diagonal in $m$ and $P$ is the applied load in N. A loading cycle of $6 \mathrm{~s}$ was used to minimize the sample creep under the indenter. Loads of 98 and $147 \mathrm{mN}$ were used to correct for the instant elastic recovery. For each load, at least eight measurements were averaged.

\section{RESULTS}

Crystallinity derived from WAXS and nanostructure

Figure 2 shows the WAXS patterns for all of the samples studied. It is important to note that, 
TABLE I

Values of $L$ from SAXS, $T_{m}, \Delta H_{m}, H, \alpha_{\mathrm{WAXS}}, l_{c}$ (Derived as $l_{c} \approx L \alpha_{\mathrm{WAXS}}$ ), and $H_{c}$ of the Aliphatic Polyesters

\begin{tabular}{cccccccc}
\hline Sample & $L(\mathrm{~nm})$ & $T_{m}\left({ }^{\circ} \mathrm{C}\right)$ & $\Delta H_{m}(\mathrm{~J} / \mathrm{g})$ & $H(\mathrm{MPa})$ & $\alpha_{\text {WAXs }}$ & $l_{c}(\mathrm{~nm})$ & $H_{c}(\mathrm{MPa})$ \\
\hline 1 & 11.5 & 56.2 & 106.6 & $42 \pm 3$ & 0.70 & 8.0 & 60 \\
2 & 10.0 & 62.3 & 119.7 & $33 \pm 3$ & 0.55 & 5.5 & 60 \\
3 & $* 11.4$ & 60.1 & 80.1 & $29 \pm 2$ & 0.58 & $* 6.7$ & 50 \\
4 & 10.4 & 52.8 & 93.7 & $25 \pm 2$ & 0.51 & 5.3 & 49 \\
5 & 11.4 & 43.0 & 51.8 & $27 \pm 2$ & 0.54 & 6.1 & 50 \\
6 & 10.1 & 60.0 & 74.2 & $28 \pm 3$ & 0.50 & 5.0 & 57 \\
\hline
\end{tabular}

The $L$ and $l_{c}$ values for sample 3 are indicated with an asterisk (see the text for an explanation).

whereas samples 1 and 2 were well characterized from the crystallographic point of view, ${ }^{8,13-17}$ there was a lack of crystallographic information about samples 3,4 , and 6 . The existing data were very scarce and poor. ${ }^{18,20}$ In addition, to our knowledge, the diffractogram corresponding to poly(butynediol adipate), sample 5, has never been reported before. All of the diffractograms showed a diffraction maximum at 21.3-21.6 $6^{\circ}$ ( $2 \theta$; where $\theta$ is the scattering angle). The $\alpha_{\text {WAXS }}$ value of every sample was calculated as the ratio of the area corresponding to the crystalline peaks to the total area of the diffractogram. The $\alpha_{\text {WAXS }}$ values ranged between 0.5 and 0.7 (see Table I).

Figure 3 shows the SAXS patterns of all of the samples, that is, the scattering intensity as a function of the reciprocal vector $s\left(\mathrm{~nm}^{-1} ; s=2 \sin \theta / \lambda\right.$, and $\lambda$ $=0.15 \mathrm{~nm}$ ). From the maxima position, the long spacing $L$ corresponding to each sample could be derived $(L=1 / s)$.

The values for $L$ derived from the SAXS maxima, $\alpha_{\mathrm{WAXS}}$, and crystal thickness $\left(l_{c} \approx L \alpha_{\mathrm{WAXS}}\right)$ obtained from these polyesters are listed in Table I. As we did not have information about the $L$ value for sample 3, we assumed that, similarly to samples 1 and $5, L \approx 11.4 \mathrm{~nm}$ for this sample, and consequently, $l_{c} \approx 11.4 \times 0.58=6.7 \mathrm{~nm}$. The $L$ and $l_{c}$ values for sample 3 are indicated with an asterisk in Table I.

Most of the crystallographic data of these polyesters that appear in the literature corresponded to sample 1, poly(butanediol adipate). ${ }^{8,13-16}$ It is known that this polyester can crystallize in two crystalline forms, $\alpha$ (monoclinic) and $\beta$ (orthorhombic), 11,13,14,16 with the $\alpha$ form being the most stable from the structural point of view. ${ }^{11}$ In this study, we dealt with the $\alpha$ form of sample 1 (see Fig. 2). Assuming, in a first approximation, that $l_{c} \approx L \alpha_{\mathrm{WAXS}}$, we found, for sample 1 , a value of $l_{c} \approx 11.5 \times 0.7=8.0 \mathrm{~nm}$. Interestingly, in refs. 11 and 12 , slightly different values of $L$ and $l_{c}$ are listed for sample 1 . Thus, taking into account the information given in ref. ${ }^{11}, L$ and $l_{c}$ were about 14.3 and $7.4 \mathrm{~nm}$ for the $\beta$ form and 15.7 and $9.0 \mathrm{~nm}$ for the $\alpha$ form. From ref. ${ }^{12}$, the $l_{c}$ values corresponding to the $\alpha$ and $\beta$ form were 8.5 and $7.0 \mathrm{~nm}$, respectively.

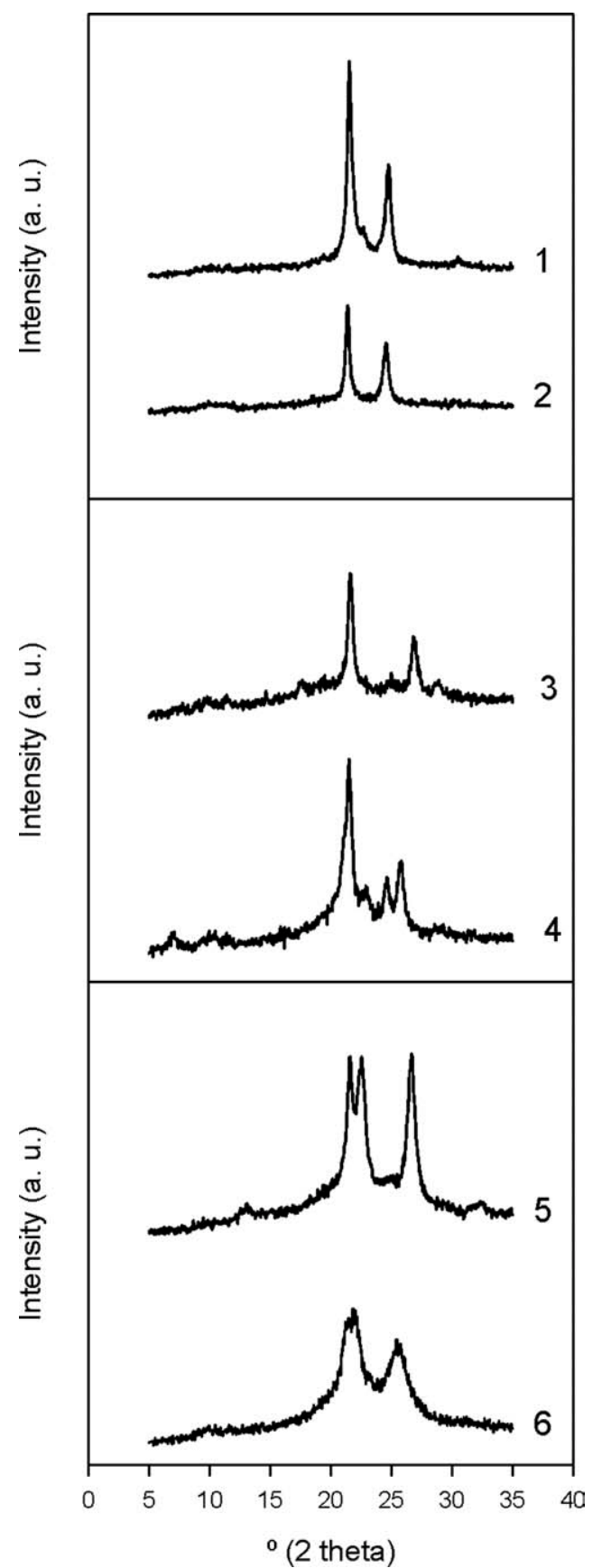

Figure 2 WAXS diagrams of the studied aliphatic polyesters (for sample identification, see Fig. 1). 


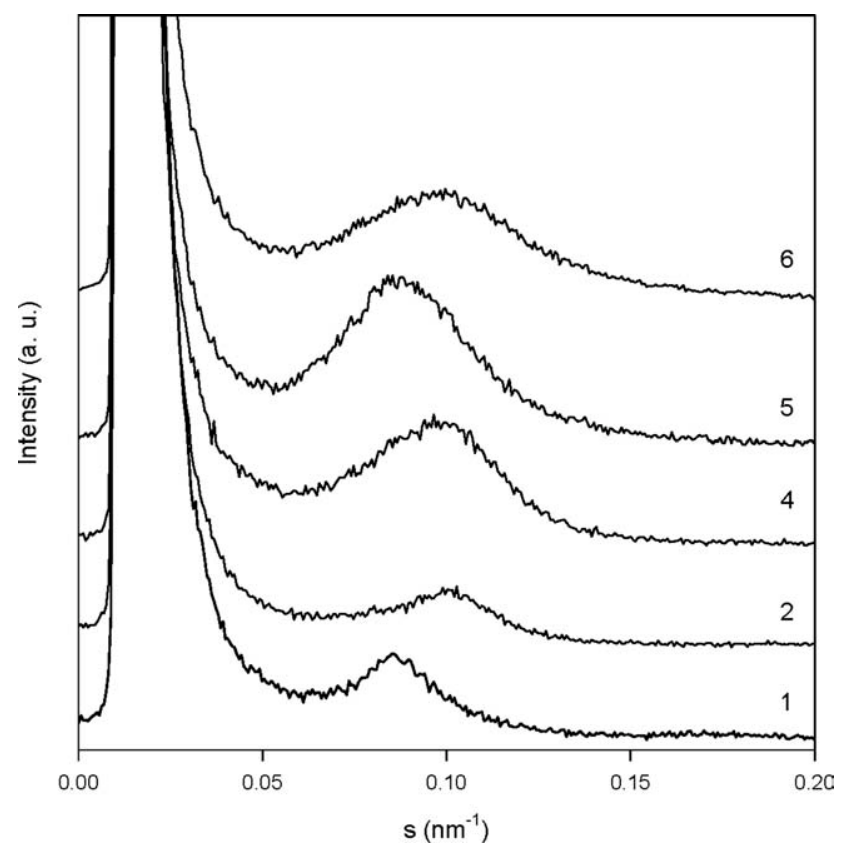

Figure 3 SAXS patterns of the investigated materials (for sample identification, see Fig. 1).

For sample 2, poly(butanediol sebacate), it has been shown that this polyester crystallizes in the orthorhombic system, with the main crystallographic constants having been determined by Almontassir et al. ${ }^{17}$

\section{Thermal behavior}

The DSC curves are shown in Figure 4. As shown in Table I, all of the samples presented low $T_{m}$ 's. In these experiments, the heating runs could not start at temperatures lower than room temperature. For this reason, we concluded that, at least in case of sample 5 , the obtained $\Delta H_{m}$ value could have been lower than the real one.

Among the different values of the melting enthalpy of a $100 \%$ crystalline material $\left(\Delta H_{\mathrm{m}}^{0}\right)_{12}^{7-9}$ and the equilibrium melting temperature $\left(T_{\mathrm{m}}^{0}\right)^{9-12}$ found in the literature for the $\alpha$ form of poly(butanediol adipate), we selected values of $\Delta H_{\mathrm{m}}^{0}=123.9 \mathrm{~J} / \mathrm{g}^{7}$ and $T_{\mathrm{m}}^{0}=63^{\circ} \mathrm{C}^{10}{ }^{10}$ The crystalline density $\left(\rho_{c}\right)$ of sample 1 was $1.23 \mathrm{~g} / \mathrm{cm}^{3} .9,15$ According to the Thomson-Gibbs equation

$$
T_{m}=T_{m}^{0}\left[1-\left(2 \sigma_{e} / \Delta H_{m}^{0} \rho_{c} l_{c}\right)\right]
$$

Substituting $T_{m}, T_{\mathrm{m}}^{0}, \Delta H_{\mathrm{m}}^{0}, \rho_{c}$, and $l_{c}$ with their corresponding values, we derived the free surface energy $\left(\sigma_{e}\right)$ for sample 1 as $\sigma_{e}=12.3 \mathrm{erg} / \mathrm{cm}^{2}$. This value was notably lower than the ones derived for the poly(ethylene) (PE) samples $\left(\sigma_{e}=79-91 \mathrm{erg} /\right.$ $\left.\mathrm{cm}^{2}\right)^{27}$ or for the poly(ethylene oxide) samples $\left(\sigma_{e}=\right.$ $\left.41-66 \mathrm{erg} / \mathrm{m}^{2}\right){ }^{28}$

\section{Microindentation hardness}

According to the two-phase model, the hardness of a semicrystalline polymer is given by the following equation: $^{29}$

$$
H=H_{c} \alpha+H_{a}(1-\alpha)
$$

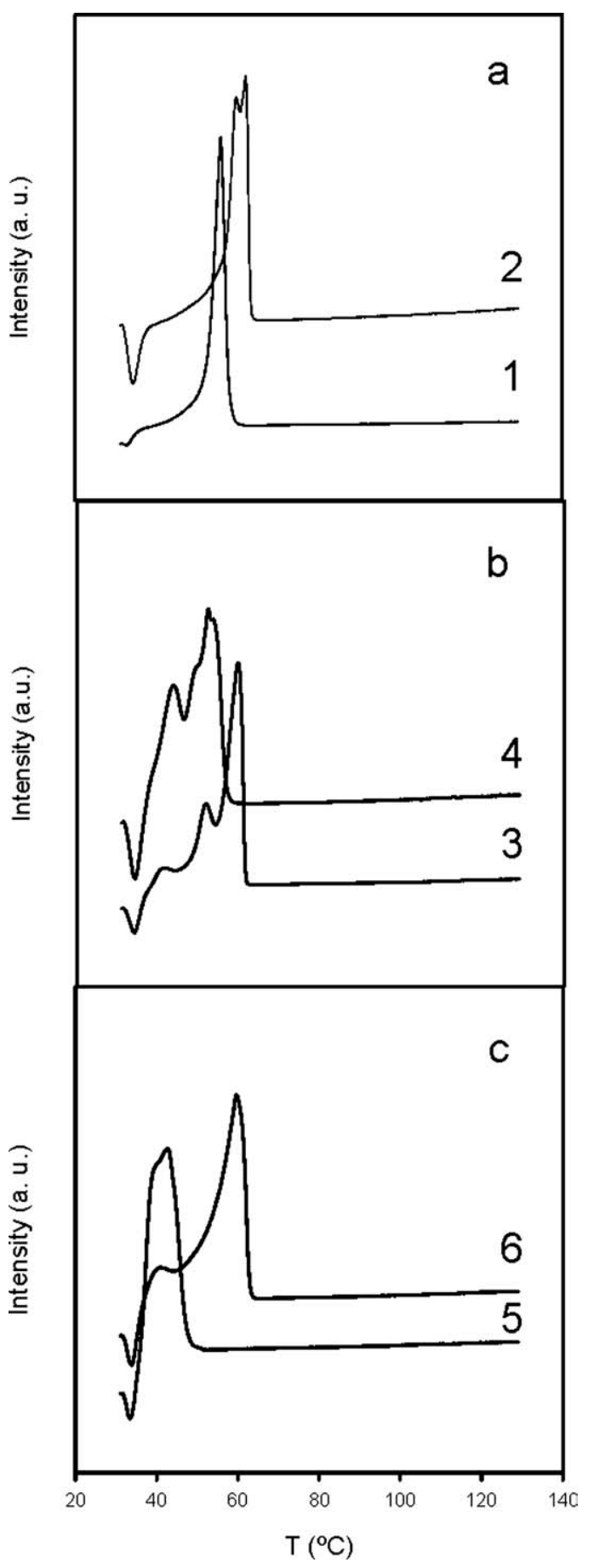

Figure 4 DSC diagrams of (a) saturated polyesters based on 1,4-butanediol (samples 1 and 2), (b) unsaturated polyesters based on 1,4-cis-butenediol (samples 3 and 4), and (c) unsaturated polyesters based on 1,4-butynediol (samples 5 and 6). $\mathrm{T}$ is temperature in ${ }^{\circ} \mathrm{C}$. 


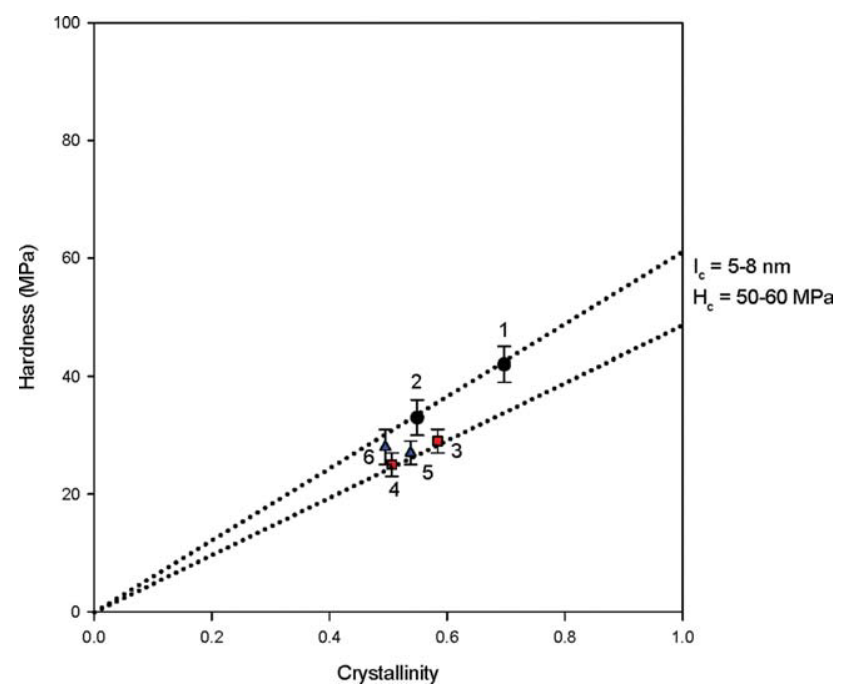

Figure 5 Dependence of $H$ on $\alpha$ of the studied polyesters (for sample identification, see Fig. 1). [Color figure can be viewed in the online issue, which is available at www.interscience.wiley.com.]

where $H_{c}$ and $H_{a}$ are the crystalline and amorphous hardnesses values, respectively, and $\alpha$ is the degree of crystallinity. From preceding publications, ${ }^{5,6,7-9}$ we knew that all of the samples under study present $T_{g}$ values well below $0^{\circ} \mathrm{C}$. Because in all cases, $H_{a} \approx$ 0 , eq. (2) can be written as

$$
H \approx H_{c} \alpha
$$

Thus, from eq. (3), we derived $H_{c}$ for all of the samples as $H_{c} \approx H / \alpha_{\text {WAxs. }}$. The $H_{c}$ values are also collected in Table I.

Figure 5 illustrates the dependence of the hardness with $\alpha$ for the investigated polyesters. For the three sets of samples, $H$ increased with $\alpha_{\text {WAXs. }}$. All of the hardness data were located in an area in which $l_{c}$ varied between 5 and $8 \mathrm{~nm}$ and $H_{c}$ varied between 50 and $60 \mathrm{MPa}$. Although samples 1 and 2, on one side, and samples 3, 4, and 5, on the other side, showed similar $H_{c}$ values, that is, 60 and $50 \mathrm{MPa}$, respectively, sample 6 presented an intermediate $H_{c}$ value of about $57 \mathrm{MPa}$.

\section{DISCUSSION}

The hardness dependence upon $\alpha$ for the polyesters under study was similar to the one shown by polyolefins such as linear polyethylene (see Fig. 10 in ref. 30). However, the values exhibited by linear PE for $H(67-76 \mathrm{MPa})$ and $H_{c}(86-93 \mathrm{MPa})$ were notably higher. ${ }^{27}$

Figure 6 shows the relationship between $H_{c}$ and the reciprocal of $l_{c}\left(1 / l_{c}\right)$ for all of the samples under study. By extrapolation of the regression line, a hardness value for infinitely long crystals $\left(H_{\mathrm{c}}^{\infty}\right)$ of 64
MPa was obtained. This value was also much lower than $170 \mathrm{MPa}$, which is the ideal hardness of an infinitely thick PE crystal. ${ }^{25}$ From $H_{\mathrm{c}}^{\infty}=64 \mathrm{MPa}$, and with the following expression taken into account $^{29}$

$$
H_{c}=H_{c}^{\infty} /\left(1+b / l_{c}\right)
$$

one obtains for the $b$ parameter (a measure of the hardness depression from $H_{c}^{\infty}$ ) a value of $1.1 \mathrm{~nm}$. This value was very close to the one derived for the $\alpha$ form of the aromatic polyester poly(butylene terephthalate) (PBT). For PBT, $b=1.5 \mathrm{~nm} \cdot{ }^{23}$ This was an indication that the degree of disorder at the crystal surface was similar for both kinds of polymers, that is, PBT and the aliphatic polyesters included in this study. However, PBT exhibited much higher $H$, $H_{c}$, and $H_{c}^{\infty}$ values $(153,287$, and $370 \mathrm{MPa}$, respectively). ${ }^{23,24^{c}}$ These large differences may have originated with the presence in PBT of the terephthalic acid aromatic units, which conferred a much higher rigidity on the polymeric chains. The aromatic units are also responsible for the high hardness values exhibited by other aromatic polyesters, such as poly(ethylene terephthalate) $\left(H=220 \mathrm{MPa}, H_{c}=287\right.$ $\mathrm{MPa}, H_{\mathrm{c}}^{\infty}=380 \mathrm{MPa}$, and $\left.b=1.9 \mathrm{~nm}\right)^{31}$ and poly (ethylene naphthalene-2,6-dicarboxylate) $(H=300$ $\mathrm{MPa}, H_{c}=341 \mathrm{MPa}^{31} H_{\mathrm{c}}^{\infty}=550 \mathrm{MPa}$, and $b=$ $1.8 \mathrm{~nm}){ }^{32}$ For the same reason, the $T_{m}$ 's of these aromatic polyesters were $221^{\circ} \mathrm{C}$ for $\mathrm{PBT}^{33} 260-270^{\circ} \mathrm{C}$ for poly(ethylene terephthalate), ${ }^{34}$ and $270^{\circ} \mathrm{C}$ for poly(ethylene naphthalene-2,6-dicarboxylate) ${ }^{35}$ these

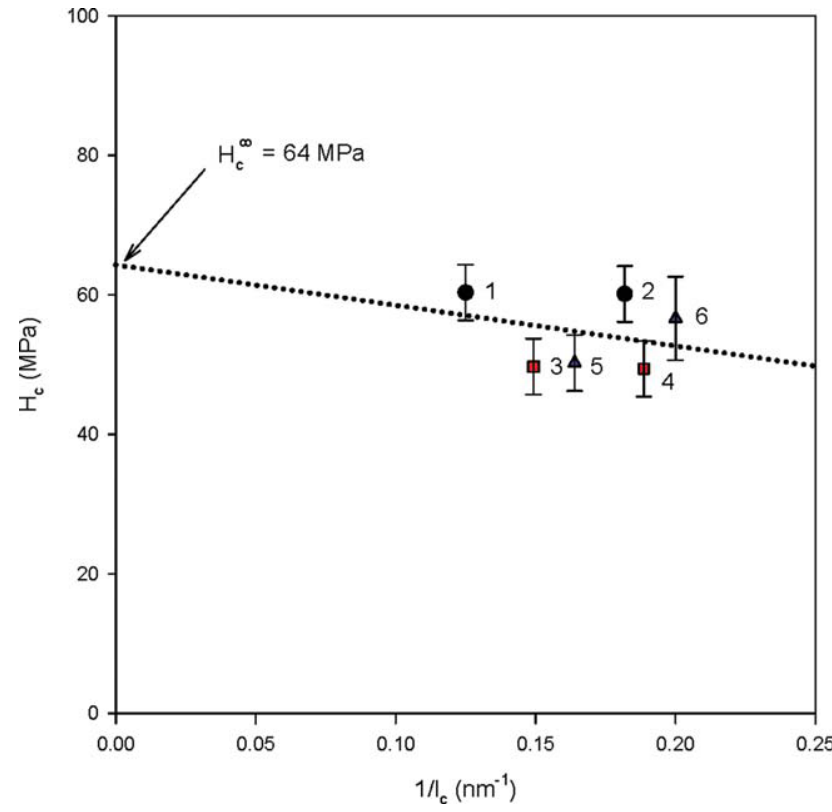

Figure 6 Relationship between $H_{c}$ and $1 / l_{c}$ of the studied polyesters (for sample identification, see Fig. 1). [Color figure can be viewed in the online issue, which is available at www.interscience.wiley.com.] 
were much higher than those values exhibited by the aliphatic polyesters included in this study, which ranged between 43 and $62.3^{\circ} \mathrm{C}$ (see Table I).

As shown in Table I, the $T_{m}$ and the $\Delta H_{m}$ values for sample 1 were lower than for sample 2. However, $H$ for the former was higher than for the latter. This was probably due to the fact that the $\alpha$ and $l_{c}$ values for sample 1 were larger than for sample 2 . When compared the features of samples 1 and 2 with those of the well-known polyester poly( $\varepsilon$-caprolactone), we determined that some characteristics of the latter were similar to those exhibited by poly(butanediol adipate) and poly(butanediol sebacate). Thus, poly(e-caprolactone) had a $T_{m}$ of about $56^{\circ} \mathrm{C}_{;}^{36}$ in addition, according to ref. ${ }^{37}, T_{\mathrm{m}}^{0}=69.2^{\circ} \mathrm{C}$ and $\Delta H_{\mathrm{m}}^{0}=157 \mathrm{~J} / \mathrm{g}$. Taking into account the crystallographic data published in ref. ${ }^{38}$, we determined the $\rho_{c}$ of poly( $\varepsilon$-caprolactone) to be about $1.18 \mathrm{~g} / \mathrm{cm}^{3}$. We had no data concerning $H$ of poly(e-caprolactone). However, from Tabor's relation, $H / \sigma_{y} \approx 3{ }^{39}$ with the yield stress value listed in ref. ${ }^{40}$ for this polymer, that is, $\sigma_{y}=4.91 \mathrm{MPa}, H$ should have been about $15 \mathrm{MPa}$; this value was notably lower than the values found for samples 1 and 2 (see Table I). From the foregoing, it seems clear that poly(butanediol adipate) and poly(butanediol sebacate) exhibited better mechanical properties than poly( $\varepsilon$-caprolactone).

\section{CONCLUSIONS}

The analysis of the data offers a correlation between the nanostructure and the micromechanical properties of these biodegradable systems. It turns out that poly(butanediol adipate), sample 1, with the highest $\alpha_{\text {WAXS }}$, exhibits the largest hardness values.

The aliphatic polyesters included in this study show a $H-\alpha_{\text {WAXS }}$ relationship similar to that found in linear PE. However, $H_{c}$ and the calculated hardness values for infinitely thick crystals are much lower that those of linear PE.

Although the value derived for the $b$ mechanical parameter of the aliphatic polyesters is similar to that of PBT, the latter shows notably higher thermal and mechanical properties because of the presence of aromatic cycles in the monomeric units.

The saturated polyesters poly(butanediol adipate) and poly(butanediol sebacate) exhibit slightly higher $H$ values than poly(e-caprolactone), also a biodegradable polyester that has found a wide variety of applications in recent years.

\section{References}

1. Vert, M. Biomacromolecules 2005, 6, 538 .

2. Edlund, U.; Albertsson, A.-C. Adv Drug Delivery Rev 2003, $55,585$.

3. Bastioli, C. Macromol Symp 1998, 135, 193.
4. Kricheldorf, H. R.; Langanke, D.; Spickermann, J.; Schmidt, M. Macromolecules 1999, 32, 3559.

5. Chatti, S.; Behnken, G.; Langanke, D.; Kricheldorf, H. R. Macromol Chem Phys 2006, 207, 1474.

6. Kricheldorf, H. R.; Gao, Q.; Buzin, P.; Schwartz, G. Macromol Chem Phys 2008, 209, 385.

7. Rabinovitch, B.; Nistratov, V. P.; Babinkov, A. G.; Shvetsova, K. G.; Larina, V. N. Polym Sci USSR 1984, 26, 826.

8. Nikolic, M. S.; Djonlagic, J. Polym Degrad Stab 2001, 74, 263.

9. Penning, J. P.; St. John Manley, R. Macromolecules 1996, 29, 77.

10. Righetti, M. C.; Pizzoli, M.; Lotti, N.; Munari, A. Macromol Chem Phys 1998, 199, 2063.

11. Gan, Z.; Kuwabara, K.; Abe, H.; Iwata, T.; Doi, Y. Biomacromolecules 2004, 5, 371 .

12. Gan, Z.; Kuwabara, K.; Abe, H.; Iwata, T.; Doi, Y. Polym Degrad Stab 2005, 87, 191.

13. Pouget, E.; Almontassir, A.; Casas, M. T.; Puiggalí, J. Macromolecules 2003, 36, 698.

14. Gan, Z.; Abe, H.; Doi, Y. Macromol Chem Phys 2002, 203, 2369.

15. Noguchi, K.; Kondo, H.; Ichikawa, Y.; Okuyama, K.; Washiyama, J. Polymer 2005, 46, 10823.

16. Zhao, L.; Wang, X.; Li, L.; Gan, Z. Polymer 2007, 48, 6152.

17. Almontassir, A.; Gestí, S.; Franco, L.; Puiggalí, J. Macromolecules 2004, 37, 5300.

18. Pourjavadi, A.; Zohourian, M. J. J Polym Mater 1993, 10, 233.

19. Vlad, S.; Oprea, S.; Stanciu, A.; Ciobanu, C.; Bulacovschi, V. Eur Polym J 2000, 36, 1495.

20. Marvel, C. S.; Young, C. H. J Am Chem Soc 1951, 73, 1066.

21. Marvel, C. S.; Young, C. H. J Am Chem Soc 1950, 72, 1674.

22. Baltá Calleja, F. J.; Salazar, J. M.; Asano, T. J Mater Sci Lett 1988, 7, 165.

23. Giri, L.; Roslaniec, Z.; Ezquerra, T. A.; Baltá Calleja, F. J. J Macromol Sci Phys 1997, 36, 335.

24. Fakirov, S.; Boneva, D.; Baltá Calleja, F. J.; Krumova, M.; Apostolov, A. A. J Mater Sci Lett 1998, 17, 453.

25. Flores, A.; Baltá Calleja, F. J.; Bassett, D. C. J Polym Sci Part B: Polym Phys 1999, 37, 3151.

26. Cagiao, M. E.; Ania, F.; Baltá Calleja, F. J.; Hirami, M.; Shimomura, T. J Appl Polym Sci 2000, 77, 636.

27. Baltá Calleja, F. J.; Santa Cruz, C.; Bayer, R. K.; Kilian, H. G. Colloid Polym Sci 1990, 268, 440.

28. Baltá Calleja, F. J.; Santa Cruz, C. Acta Polym 1996, 47, 303.

29. Baltá Calleja, F. J.; Fakirov, S. Microhardness of Polymers; Solid State Science Series; Cambridge University Press: Cambridge, England, 2000; p 11.

30. Flores, A.; Ania, F.; Baltá Calleja, F. J. Polymer 2009, 50, 729.

31. Santa Cruz, C.; Baltá Calleja, F. J.; Zachmann, H. G.; Chen, D. J Mater Sci 1992, 27, 2161.

32. Rueda, D. R.; Viksne, A.; Malers, L.; Baltá Calleja, F. J. Macromol Chem Phys 1994, 195, 3869.

33. Di Lorenzo, M. L.; La Pietra, P.; Errico, M. E.; Righetti, M. C.; Angiuli, M. Polym Eng Sci 2007, 47, 323.

34. Köncke, U.; Zachmann, H. G.; Baltá Calleja, F. J. Macromolecules 1996, 29, 6019.

35. Buchner, S.; Wiswe, D.; Zachmann, H. G. Polymer 1989, 30, 480.

36. Rosa, D. S.; Neto, I. C.; Calil, M. R.; Pedroso, A. G.; Fonseca, C. P.; Neves, S. J Appl Polym Sci 2004, 91, 3909.

37. The Advanced THermal Analysis System. http://athas.prz. rzeszow.pl. (accessed September 2008)

38. Hu, H.; Dorset, D. L. Macromolecules 1990, 23, 4604.

39. Tabor, D. Hardness of Metals; Oxford University Press: London, 2000

40. Gorrasi, G.; Tortora, M.; Vittoria, V.; Galli, G.; Chiellini, E. J Polym Sci Part B: Polym Phys 2002, 40, 1118. 